\title{
The Inheritance Pattern of Brown Lint in Color-Cotton
}

\author{
Keerthi A. Patil ${ }^{1 *}$ and Rajesh S. Patil ${ }^{2}$ \\ ${ }^{1}$ Department of Genetics and Plant Breeding, College of Agriculture, UAS, Dharwad, India \\ ${ }^{2}$ Agricultural research Station, Dharwad Farm, Dharwad, Karnataka, India \\ *Corresponding author
}

K e y w o r d s
Color-cotton,
Brown lint, $\chi 2$ test,
Gene action,
Incompletely
dominant gene
action

\section{Introduction}

Cotton, the king of fibers is the largest natural textile material worldwide. The cotton fiber with the presence of pigments intermingled with cellulose produces what is called naturally colored cotton. Since time immemorial the color and white linted cotton are found in nature, as evidenced from the excavation of Huaca Prieta on the northern Peruvian Coast of South America which indicated the usage and cultivation of colorcotton since 2500 B.C., (Stephens, 1975, Apodaca, 1990). The lint exists in various hues and the brown and green colors are most common among them. The brown color, in turn, has many shades ranging from dark brown to mahogany red.

The textile industries artificially apply the dyes to the cotton to make it colored. This results in harmful industrial discharge from dyeing industries into water bodies that risk human health and the environment. The use of naturally colored cotton eliminates the dyeing process in textiles from which about one-half of the cost of preparing fabrics can be reduced (Pooja and Anita, 2018). Furthermore, fabrics made of naturally colored cotton are steadfast compared to 
synthetically dyed clothes that do not fade quickly. Despite the economic and ecological benefits, commercial cultivation of naturally colored cotton is very limited by the farmers because of few drawbacks.

The fiber of low quality is most important among them. The fiber quality and yield are negatively associated with the fiber color which in turn makes the color-cotton less productive along with the lower quality of the fiber (Feng et al., 2015). In addition to low quality, the limited range of colors, the instability of lint color overexposure to sunlight, the need for isolated fields to avoid contamination of white cotton, and the lack of standard quality classification criteria have limited its cultivation (Matusiak and Frydrych, 2014).

The development of fiber color in cotton is genetically controlled. It was reported that the brown color has a dominant legacy (Wang et al., 2012). Kohel (1985) investigated the fiber color genes and reported six loci for brown color, namely Lc1 and Lc2 (medium brown), Lc3 (dark brown), Lc4, Lc5, and Lc6 (light brown). The inheritance study of fiber color will allow us to determine the gene action involved in lint color that could be used by crossing white linted with color linted lines in the development of more productive colorcotton varieties.

\section{Materials and Methods}

A study was carried on in the early segregating generations' viz., $\mathrm{F}_{2}$ and $\mathrm{F}_{2: 3}$ to evaluate the segregation pattern for fiber color in a cross between Sahana (white lint) and DB-50-2 (dark brown lint). The crossed $F_{1}$ seeds were selfed to generate the $F_{2}$ population. Each $\mathrm{F}_{2}$ plant was selfed to advance the generation to $F_{3}$. Both $F_{2}$ and $F_{2: 3}$ populations were examined to know the inheritance pattern for lint color.
The experiment was conducted during Kharif, 2018 and Kharif, 2019 at Agricultural Research Station, Dharwad Farm, University of Agricultural Sciences, Dharwad. Plants of the $F_{2}$ generation and $F_{2: 3}$ progenies were grown in a row of $4.2 \mathrm{~m}$ length with a spacing of $90 \mathrm{~cm}$ between rows and $20 \mathrm{~cm}$ between plants. All the recommended measures were practiced to raise a healthy crop. The agronomical and plant protection measures were carried out from sowing to harvest as per the standard recommendation.

The $F_{2}$ population and $F_{2: 3}$ populations under study were visually inspected and scored for the lint color from the completely opened boll. The brown color had segregated into many shades ranging from light to dark brown.

A Chi-square test was performed to assess the inheritance pattern for fiber color in $F_{2}$ and $\mathrm{F}_{2: 3}$ populations. The significance of the difference between observed and expected frequencies or ratios was studied using the method given by Klug and Cummings (1999). Chi-Square test ( $\chi^{2}$ test) is the summation of the squared deviation of observed and expected frequencies divided by expected frequencies given by the formula,

$\chi^{2}=\Sigma \frac{(\mathrm{O}-\mathrm{E}) 2}{\mathrm{E}}$ with $(\mathrm{n}-1)$ d.f

where,

$\mathrm{O}=$ observed frequencies

$\mathrm{E}=$ expected frequencies

$\mathrm{n}=$ number of classes

The chi-square values tested against table values with $n-1$ degrees of freedom ( $n$ is the number of classes).

The deviations were taken as significant wherever the calculated chi-square value was 
over the table value at both levels, and the presumed ratio was not considered a fit, and vice-versa.

\section{Results and Discussion}

In the cross, the fiber color of each plant in $\mathrm{F}_{1}$ was intermediate to that of the parents that confirmed the brown color of fiber had nuclear inheritance and exhibited partial dominance over white (Ware, 1932; Richmond, 1943 and Xianlong, 2004). On visual inspection of individual plants in $F_{2}$, the intensity of brown color varied showing five different shades (Fig. 1). Further, the $F_{2: 3}$ populations were studied to reconfirm the segregation pattern of fiber color. The dark brown and light brown shades did not segregate for the color trait. Hence, the progeny lines of the $\mathrm{F}_{2: 3}$ populations that segregated for fiber color were only considered for fitting the ratio. Since discrete grouping of color was not possible, the plants with similar and slightly darker shades than brown were grouped under the brown category, and the rest with lighter shades of brown were grouped in the intermediate category.

Table.1 Chi-square test in the cross Sahana (white lint) x DB-50-2 (dark brown lint) for lint color segregation

\begin{tabular}{|c|c|c|c|c|c|c|}
\hline \multirow[t]{2}{*}{ Generation } & \multirow{2}{*}{$\begin{array}{l}\text { Total no. } \\
\text { of plants }\end{array}$} & \multicolumn{2}{|c|}{ Color of lint } & \multirow[t]{2}{*}{ White } & \multirow{2}{*}{$\begin{array}{l}\text { Observed } \\
\text { ratio }\end{array}$} & \multirow{2}{*}{$\begin{array}{c}\chi^{2} \\
\text { value }\end{array}$} \\
\hline & & $\begin{array}{c}\text { Dark } \\
\text { brown }\end{array}$ & $\begin{array}{c}\text { Medium } \\
\text { brown }\end{array}$ & & & \\
\hline $\mathbf{P}_{1}$ & 42 & - & - & All & & \\
\hline $\mathbf{P}_{2}$ & 41 & All & - & - & & \\
\hline $\mathbf{F}_{1}$ & 39 & - & All & - & & \\
\hline $\mathbf{F}_{2}$ & 345 & 101 & 160 & 84 & $1: 2: 1$ & 3.54 \\
\hline $\mathbf{F}_{3}$ & 2117 & 532 & 1048 & 537 & $1: 2: 1$ & 0.23 \\
\hline
\end{tabular}

Fig.1 Pictorial representation of the variability for fiber color of cross Sahana $\times$ DB-50-2

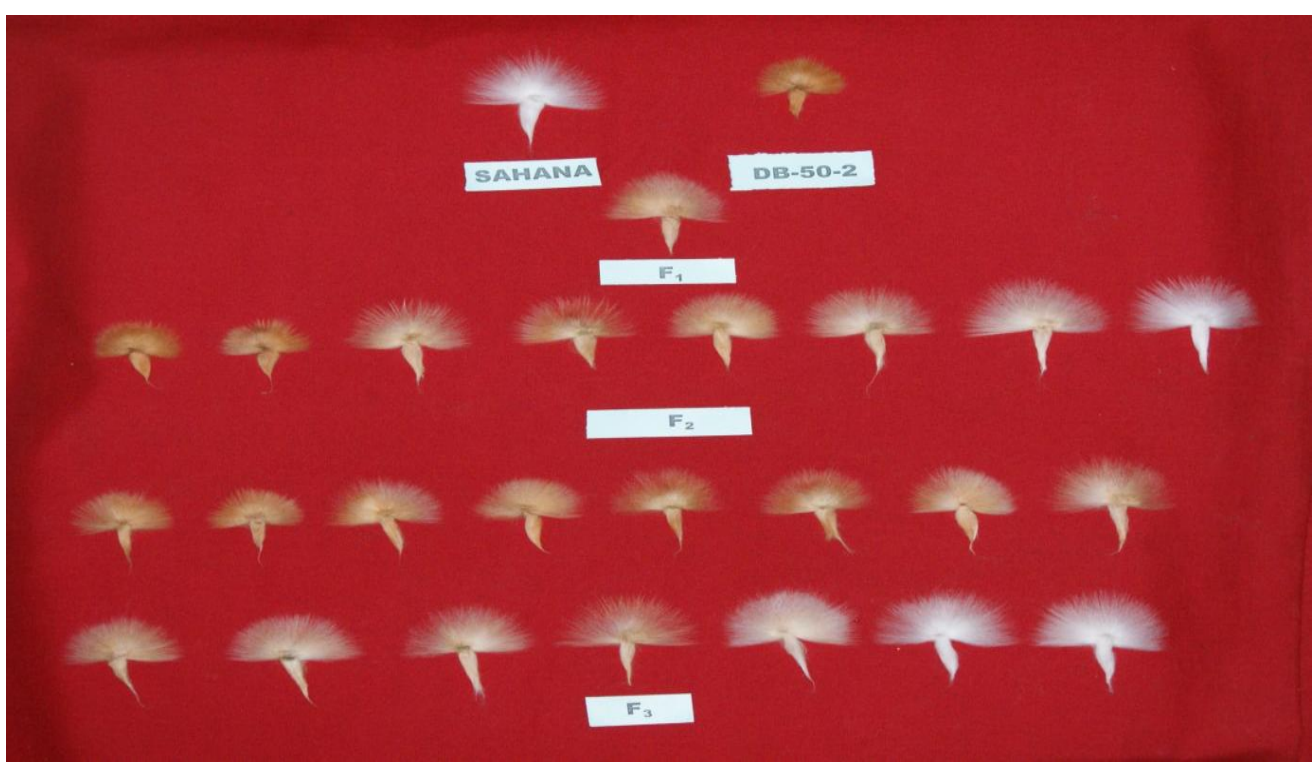


For the interpretation of results, the chi-square test of the cross indicated no significant deviation from the inheritance pattern of the 1:2:1 phenotypic ratio (Table 1). Among the 345 plants, 101 plants possessed brown color, 160 plants had intermediate color, and 84 plants were white. Further, the $F_{2: 3}$ populations were studied to reconfirm the segregation pattern of fiber color. Among the 2117 plants, 532 showed brown color, 1048 carried intermediate color, and 537 plants had white color. In the chi-square analysis, the pvalue was more than 0.05 implying the acceptance of the null hypothesis. The $\mathrm{F}_{2}$ and $\mathrm{F}_{2: 3}$ populations segregated into different shades of color and white that fit well into the expected ratio of $1: 2: 1$. This portrayed that the brown color was controlled by a single incompletely dominant gene. A similar result was noticed by Nivedha et al., (2020), Shaohua et al., (2008), and Hinchliffe et al., (2016).

Even though the ratio supported single gene inheritance, the varying intensity of brown color in $F_{2}$ and $F_{2: 3}$ rather than two discrete color phenotype classes paved the way for the possibility of more than one locus responsible for color as proposed by Kohel (1985). Wang et al., (2014) reported that the modification of minor genes could have accounted for variations in the $F_{2}$ population. Therefore, further studies should be carried for judging the number of loci governing brown lint color trait in cotton.

\section{References}

Apodaca, J. K. 1990. Naturally colour cotton: A new niche in the Texas Natural Fibers. BBR Working Paper Series, Bureau of Business Research, University of Texas at Austin.

Feng, H., Guo, L., Wang, G., Sun, J., Pan, Z., He, S., Zhu, H., Sun, J., and Du, X. 2015. The negative correlation between fiber color and quality traits revealed by QTL analysis. PLoS ONE, 10(6): e0129490.

Hinchliffe, D. J., Condon, B. D., Thyssen, G., Naoumkina, M., Madison, C. A. Reynolds, M., Delhom, C. D., Fang, D. D., Li, P., and McCarty, J. 2016. The GhTT2_A07 gene is linked to the brown colour and natural flame retardancy phenotypes of Lc1 cotton (Gossypium hirsutum L.) fibers. Journal of experimental botany, 67(18): 5461-5471.

Klug, W. S., and Cummings, M. R. 2006. Concepts of genetics. Pearson Education, Upper Saddle River, New Jersey.

Kohel, R. J. 1985. Genetic Analysis of Fiber Color Variants in Cotton. Crop Science, 25(5): 793-797.

Matusiak, M., and Frydrych, I. 2014. Investigation of Naturally Coloured Cotton of Different Origin-Analysis of Fiber Properties. FIBERS \& TEXTILES in Eastern Europe, 5(107): 34-42.

Nivedha, R., Rajeswari, S., Premalatha, N., and Sritharan, N. 2020. Inheritance study for lint colour in naturally brown coloured upland cotton (Gossypium hirsutum L.). Electronic Journal of Plant Breeding, 11(2): 550-555.

Pooja, B., and Anita, R. 2018. Naturally coloured cotton: a brief review. Journal of Cotton Research and Development, 32(1): 161-166.

Richmond, T. R. 1943. Inheritance of green and brown lint in upland cotton. Journal of the American Society of Agronomy, 35: 967-975.

Shaohua, Z., Zhengpeng, L., Yi, L., and Yongping, C. 2008. Quantitative Analysis on the Inherited Characteristics of Naturally Colored Brown Cotton Fiber Color. Chinese Agricultural Science Bulletin, 12. 
Stephens, S. G. 1975. A re-examination of the cotton remains from Huaca Prieta, North Coastal Peru. American Antiquity, 40(4): 406-418.

Wang, L. X., Liu, H. F., Xiao, X. W., Pang, Z. Q., Song, W., Lu, C. F., Luo, C., Liu, G. Y., Xu, J. C., Li, X. B., and Li, X. B. 2012. Studies on hereditary properties of colored cotton in Xinjiang. Agricultural Science \& Technology- Hunan, 13(3): 541-582.
Luo, C., Zhu, L., Li, X. 2014. Genetic mapping of fiber color genes on two brown cotton cultivars in Xinjiang. SpringerPlus, 3:480-484.

Ware, J. O. 1932. Inheritance of lint colors in upland cotton. Agronomy journal, 24(7): 550-562.

Xianlong, L. D. N. Y. Z. 2004. Genetic Analysis of Fiber Colour on Brown Upland Cotton. Journal of Huazhong Agricultural, 6.

\section{How to cite this article:}

Keerthi A. Patil and Rajesh S. Patil. 2021. The Inheritance Pattern of Brown Lint in ColorCotton. Int.J.Curr.Microbiol.App.Sci. 10(01): 946-950.

doi: https://doi.org/10.20546/ijcmas.2021.1001.114 